\title{
Chemical enhancement of footwear impressions in blood on fabric - part 2: peroxidase reagents
}

Kevin J. Farrugia, Niamh NicDaéid, Kathleen A. Savage, Helen Bandey and Tomasz Ciuksza

This is the accepted manuscript (C) 2010, Elsevier

Licensed under the Creative Commons Attribution-NonCommercialNoDerivatives 4.0 International:

http://creativecommons.org/licenses/by-nc-nd/4.0/

\section{(cc) EY-No-ND}

The published article is available from doi:

http://dx.doi.org/10.1016/j.scijus.2010.11.002 


\section{Chemical Enhancement of Footwear Impressions in Blood on Fabric - Part 2: Peroxidase reagents}

Kevin J. Farrugia ${ }^{a}$, Niamh NicDaéid ${ }^{a^{*}}$, Kathleen A. Savage ${ }^{a^{*}}$, Helen Bandey ${ }^{b}$, Tomasz Ciuksza ${ }^{b}$

${ }^{a}$ Centre for Forensic Science, WestCHEM, Department of Pure and Applied Chemistry, University of Strathclyde, Glasgow, G1 1XW, UK

${ }^{\mathrm{b}}$ Home Office Scientific Development Branch, Fingerprint \& Footwear Forensic Group, Woodcock Hill, Sandridge, St. Albans, AL4 9HQ, UK

\section{* CORRESPONDING AUTHORS}

Niamh Nic Daéid and Kathleen A. Savage

Centre for Forensic Science, WestCHEM, Department of Pure and Applied Chemistry,

University of Strathclyde, Glasgow, G1 1XW, UK

n.nicdaeid@strath.ac.uk

kathleen.savage@strath.ac.uk 


\begin{abstract}
This study investigates the optimisation of peroxidase based enhancement techniques for footwear impressions made in blood on various fabric surfaces. Four different haem reagents: leuco crystal violet (LCV), leuco malachite green (LMG), fluorescein and luminol were used to enhance the blood contaminated impressions.

Results indicated that all of the techniques used successfully enhanced the impressions on light coloured surfaces, however, only fluorescent and/or chemiluminescent techniques allowed visualisation on dark coloured fabrics, denim and leather. Luminol was the only technique to enhance footwear impressions made in blood on all the fabrics investigated in this study.
\end{abstract}

Keywords: footwear impressions, blood, fabric, LCV, LMG, luminol, fluorescein 


\section{INTRODUCTION}

Heme-reacting chemicals react with the heme group in haemoglobin present in blood. These chemicals, also known as peroxidase reagents, are colourless dyes that are oxidised to form a coloured product [1-2]. Compared to protein stains, these techniques are specific for blood and do not react with other body fluids, however, background staining might occur where the background is slowly oxidised to the same colour as the blood enhanced impression. Examples of heme-reacting chemicals include leuco crystal violet (LCV), leucomalachite green (LMG), benzidine, tetramethylbenzidine (TMB), phenolphthalein, fluorescein and luminol.

Haemoglobin exhibits peroxidase activity by catalysing the oxidation by peroxide of a number of organic compounds to yield coloured compounds [3]. As a result, these reactions are also known as catalytic tests. The general peroxidase reaction is as follows:

$$
\mathrm{AH}_{2}+\mathrm{ROOH} \rightarrow \mathrm{A}+\mathrm{ROH}+\mathrm{H}_{2} \mathrm{O}
$$

where $\mathrm{AH}_{2}$ is the electron donor and $\mathrm{ROOH}$ is the peroxide. The simplest peroxide is hydrogen peroxide where $\mathrm{R}=\mathrm{H}$.

Addition of hydrogen to the delocalised systems of dyes usually interferes with the absorption of visible light [4]. Figure 1 illustrates the oxidation of colourless leuco crystal violet to the purple coloured crystal violet. The leuco compound is less conjugated leading to loss of colour whereas the positive charge on the dimethyl group in crystal violet is able to delocalise over the whole molecule, imparting a bright purple colour. Organic aromatic molecules such as crystal violet with conjugated bonds, and large systems of delocalised electrons can provide visible colour and can permit molecular binding to a material [4-6] 
<smiles>CN(C)c1ccc(C(=C2C=CC(=[N+](C)C)C=C2)c2ccc(N(C)C)cc2)cc1</smiles>

Crystal Violet

Violet

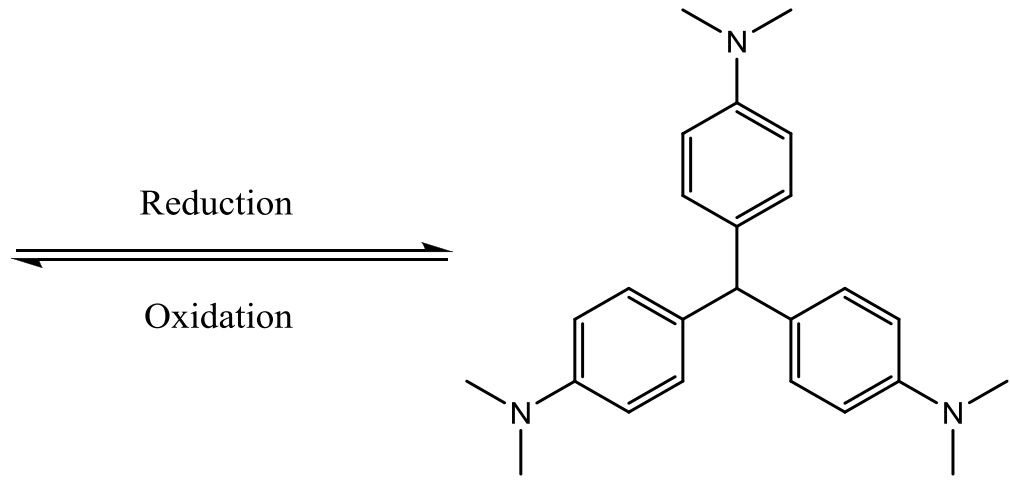

Leuco Crystal Violet

Colourless

Figure 1 - The reduction and oxidation of crystal violet and LCV

Enhancement of blood impressions with LCV and LMG utilise hydrogen peroxide $\left(\mathrm{H}_{2} \mathrm{O}_{2}\right)$ and sodium perborate $\left(\mathrm{NaBO}_{3} \cdot \mathrm{H}_{2} \mathrm{O}\right)$ respectively as the reducing agents to create an almost instantaneous colour change. Fresh solutions need to be prepared prior to use as both reagents are light and heat sensitive. Grodsky et al. [7] reported that the use of sodium perborate instead of hydrogen peroxide in the LMG formulation provided a great improvement in the reaction. The reaction between LMG and blood results in a green colour whereas the reaction of LCV and blood results in a vivid purple colour, though it has been observed that although LCV provided better contrast than LMG, it may not be as sensitive as the protein stains acid black 1, acid violet 17 and benzoxanthene yellow [8]. Recent research [9-10] has reported the development of a simple, quick, one-step method for the recovery and enhancement of blood contaminated footwear impressions using nylon membranes, previously impregnated with LMG or LCV to provide excellent enhancement and lifting simultaneously.

The formulations of LCV and LMG have the advantage of incorporating the fix, allowing the blood impression to be fixed and enhanced at the same time [11-12]. Furthermore, LCV enhanced impressions can potentially fluoresce and luminesce in the ultra-violet and infra-red spectral regions [13]. A de-staining procedure is not necessary for peroxidase reagents, but if heavy staining occurs, for example on porous surfaces, it has been suggested that the item can be rinsed with water for 2 to 3 minutes after the reagents have been applied [11]. Theeuwen et al. [14] have reported LCV as an excellent technique specifically for the enhancement of footwear impressions in blood. 
Fluorescein has a chemical structure similar to sulfonated protein stains such as acid black 1 and acid yellow 7. It is, however, applied as a heme-reagent for the detection of blood with the additional advantage of green fluorescence when illuminated with light at a wavelength of $450 \mathrm{~nm}$. The application of fluorescein for the detection of blood in forensic science has been developed by Cheeseman [15-17]. Fluorescein is soluble in alkali hydroxides and carbonates at room temperature and is reduced from fluorescein to fluorescin in alkaline solution over zinc. In contact with blood, fluorescin is quickly oxidised back to fluorescein by the catalytic activity of the heme in the presence of hydrogen peroxide [1,3]. Several studies have shown that there is no interference with the fluorescein reaction and the subsequent DNA analysis [18-21].

Luminol has been used for many years as a presumptive test for the detection of blood and various formulations of the reagent have been reported in the literature. There are also commercial formulations now available, most notably produced by Bluestar ${ }^{\circledR}$. Luminol utilises the peroxidase-like activity of the heme group in blood for the production of light and as such is a chemiluminescent test. Sears et al. [8] suggest that this method may be useful for the detection of footwear impressions in blood on dark and patterned carpets but reported that diffusion of the fine detail can occur in the enhancement of some blood-contaminated marks such as fingerprints. Other research has highlighted the sensitivity of luminol where blood was detected through eight layers of paint [22]. Luminol requires the use of specialised photography for visualisation and different formulations of luminol have varying durations of light levels which can sometimes be disadvantageous.

The results obtained from luminol must be interpreted carefully since the reagent is known to give false positives, mainly for bleach which is commonly used for crime scene cleanup [2330], however, it has been suggested that experienced users of the reagent can distinguish between the reaction of luminol with blood and bleach [1, 24, 31-32]. More recently it has been shown that luminol's reaction with bleach is greatly varied depending on the formulation of reagent used, the concentration and origin of the bleach and the period of time the bleach has had to dry [33]. Luminol is a useful technique for the enhancement of latent bloodstains and does not interfere with the analysis of DNA [34]. Luminol has been demonstrated to produce false positives with a variety of materials including household products (e.g. oil-based paints, alkyd varnish), food products (e.g. leek, ginger, carrot) and 
chemical products (e.g. $\mathrm{CuSO}_{4}, \mathrm{FeSO}_{4}$ ) [15, 35]. It is thought that ions such as $\mathrm{Cu}^{2+}, \mathrm{Fe}^{2+}$ and $\mathrm{Mn}^{2+}$ catalyse the chemiluminescence reaction of luminol whereas $\mathrm{SO}_{4}{ }^{2-}$ does not. Bluestar $^{\circledR}$ luminol, when compared to other luminol formulations has been reported as producing brighter and longer chemiluminescence, is easier to prepare, visualise and photograph and is more efficient in detecting latent bloodstains after attempted cleaning by both soapy water and bleach [23-24, 32, 36-37].

While previous studies have reported on the abilities of peroxidase reagents to enhance blood impressions, no work has to date compared the range of currently used reagents on the enhancement of repetitive marks in blood prepared under the exact same conditions and across a variety of fabric types. This study compares the effectiveness of four peroxidase reagents commonly reported in the literature to enhance repetitive marks made in blood on nine different fabric types. The fabrics investigated included natural and synthetic material of a range of colours and porosity. 


\section{MATERIALS AND METHODS}

The peroxidases reagents and fabrics utilised in the study are listed in table 1.

Table 1 - List of Peroxidase Reagents and Fabrics

\begin{tabular}{|c|c|c|c|c|}
\hline \multicolumn{5}{|c|}{ Peroxidase Reagents and Fabric } \\
\hline Chemical Name & $\begin{array}{c}\text { Alternative Chemical } \\
\text { Name }\end{array}$ & $\begin{array}{l}\text { Chemical } \\
\text { Supplier }\end{array}$ & Fabric & Fabric Supplier \\
\hline $\begin{array}{l}\text { Leucocrystal violet } \\
\text { (LCV) }\end{array}$ & $\begin{array}{c}4,4^{\prime}, 4^{\prime \prime}- \\
\text { Methylidynetris }(N, N- \\
\text { dimethylaniline })\end{array}$ & $\begin{array}{l}\text { Sigma } \\
\text { Aldrich }\end{array}$ & $\begin{array}{l}\text { White Cotton } \\
\text { (WC) }\end{array}$ & $\begin{array}{l}\text { WBL Whaleys } \\
\text { Bradford Ltd. }\end{array}$ \\
\hline $\begin{array}{c}\text { Leucomalachite } \\
\text { Green (LMG) }\end{array}$ & $\begin{array}{c}4,4^{\prime} \text {-Benzylidenebis }(N, N \text { - } \\
\text { dimethylaniline })\end{array}$ & $\begin{array}{l}\text { Sigma } \\
\text { Aldrich }\end{array}$ & $\begin{array}{c}\text { Black Cotton } \\
\text { (BC) }\end{array}$ & $\begin{array}{l}\text { WBL Whaleys } \\
\text { Bradford Ltd. }\end{array}$ \\
\hline Fluorescein & Acid Yellow 73 & $\begin{array}{l}\text { Sigma } \\
\text { Aldrich }\end{array}$ & $\begin{array}{c}\text { Patterned } \\
\text { Cotton (PC) }\end{array}$ & $\begin{array}{l}\text { WBL Whaleys } \\
\text { Bradford Ltd. }\end{array}$ \\
\hline \multirow[t]{6}{*}{ Luminol } & 3-Aminophthalhydrazide & $\begin{array}{l}\text { Bluestar } \\
\text { Forensic }\end{array}$ & $\begin{array}{c}\text { White Polyester } \\
\text { (WPE) }\end{array}$ & $\begin{array}{l}\text { WBL Whaleys } \\
\text { Bradford Ltd. }\end{array}$ \\
\hline & & & $\begin{array}{c}\text { Black Polyester } \\
\text { (BPE) }\end{array}$ & $\begin{array}{l}\text { WBL Whaleys } \\
\text { Bradford Ltd. }\end{array}$ \\
\hline & & & $\begin{array}{l}\text { White Nylon/ } \\
\text { Lycra (WNL) }\end{array}$ & $\begin{array}{l}\text { WBL Whaleys } \\
\text { Bradford Ltd. }\end{array}$ \\
\hline & & & $\begin{array}{l}\text { Black Nylon/ } \\
\text { Lycra(BNL) }\end{array}$ & $\begin{array}{l}\text { WBL Whaleys } \\
\text { Bradford Ltd. }\end{array}$ \\
\hline & & & Denim & $\begin{array}{c}\text { Mandors, } \\
\text { Glasgow, UK }\end{array}$ \\
\hline & & & Bovine Leather & $\begin{array}{l}\text { The Clyde } \\
\text { Leather Co., } \\
\text { Glasgow, UK }\end{array}$ \\
\hline
\end{tabular}




\section{Peroxidase Regent Formulations}

\section{LCV formulation:}

LCV was prepared using the formulation suggested by Bodziak [11] incorporating the fix 5sulfosalicylic acid dihydrate for a one-step process. $10 \mathrm{~g}$ of 5 -sulphosalicyclic acid was dissolved in $500 \mathrm{~mL}$ of $3 \%$ hydrogen peroxide. $3.7 \mathrm{~g}$ sodium acetate was added to the mixture followed by $1 \mathrm{~g}$ of leuco crystal violet and stirred using a magnetic stirrer until completely dissolved. The reagent was applied by spraying with an Ecospray ${ }^{\circledR}$ unit supplied by Bluestar ${ }^{\circledR}$ Forensic.

\section{LMG formulation:}

The LMG formulation utilised in this study was prepared as suggested by the RCMP [38]. 0.2 $\mathrm{g}$ of leucomalachite green was dissolved in $67 \mathrm{~mL}$ of methanol using a clean, dry, glass beaker. To this was added $33 \mathrm{~mL}$ of glacial acetic acid and $0.67 \mathrm{~g}$ of sodium perborate and the solution stirred using a magnetic stirrer until the LMG had completely dissolved. $300 \mathrm{~mL}$ of HFE 7100 was finally added and the solution stirred. The resulting solution was stored in a dark coloured glass bottle and was applied by spraying with a Preval ${ }^{\circledR}$ sprayer.

\section{Fluorescein}

The fluorescein formulation was prepared according to Cheeseman [15-17].

Solution A: A $10 \% \mathrm{NaOH}$ solution was prepared by dissolving $10 \mathrm{~g}$ of $\mathrm{NaOH}$ in $100 \mathrm{~mL}$ of distilled water. $1 \mathrm{~g}$ of fluorescein was dissolved in $100 \mathrm{~mL}$ of the $10 \% \mathrm{NaOH}$ solution. The fluorescein solution was stirred and heated gently before adding $10 \mathrm{~g}$ of zinc powder and the solution brought to a gentle boil before being left to cool. The cooled solution was then decanted carefully to remove the zinc which was neutralised prior to disposal. A 1:20 ratio of this solution with distilled water was then prepared.

Solution B: A $10 \% \mathrm{H}_{2} \mathrm{O}_{2}$ solution was prepared by using $100 \mathrm{~mL} 30 \% \mathrm{H}_{2} \mathrm{O}_{2}$ and $200 \mathrm{~mL}$ distilled water.

The reagents were applied by spraying solution A followed by solution B using an Ecospray ${ }^{\circledR}$ unit supplied by Bluestar ${ }^{\circledR}$ Forensic. Fluorescence observation was carried out with a Quasar 40 using an excitation waveband of 385-509nm and a viewing filter of 510nm. 
Luminol: The luminol formulation utilised in this study was Bluestar ${ }^{\circledR}$ Forensic Magnum purchased from Bluestar ${ }^{\circledR}$ Forensic. It was prepared by dissolving the three tablets in $125 \mathrm{~mL}$ of the liquid supplied and the reagent was applied using an Ecospray ${ }^{\circledR}$ unit supplied by Bluestar $^{\circledR}$ Forensic. The best photographic quality of the resultant chemiluminescent reactions was obtained using a Canon EOS 300D digital camera set at ISO400, f 5.6, exposure of 15 seconds and white balance set on tungsten

\section{Deposition of the footwear impressions and preparation of the test marks}

The objective of this work was to compare the ability of various peroxidase reagents to enhance footwear marks, rather than mimic operational conditions normally encountered. Only when repeatability of the quality of the footwear impression produced is controlled (such that there was no variation from mark to mark) could a direct comparison of the various reagents be reliably achieved.

Variables introduced during the preparation of test footwear impressions include the pressure of the footwear sole on the receiving surface as the footwear impression is made. It can be argued that robust comparisons of footwear enhancement techniques can only be made if the test footwear impressions have been prepared in the same manner where these factors have been controlled in each case.

In this work the pressure applied to the receiving surface by the blood contaminated footwear was precisely controlled using a rig developed and calibrated for that purpose. The device was calibrated to repeatably deliver a force comparable with the average force used in a stamping action as determined through trials conducted with live volunteers (3500 Newtons).

Other influencing factors on the quality of the mark include the amount and composition of blood on the footwear sole prior to being transferred to the receiving surface and the actual amount of contaminant transferred to the substrate. The application of blood to the footwear sole and the subsequent transfer of blood to a substrate are challenging to control during experimental trials. Stepping into a pool of blood followed by stepping onto the fabric resulted in a heavy blood-stained and overloaded footwear impression. The following method however yielded reasonably weak and reproducible bloody impressions from mark to mark. A tray measuring $0.33 \times 0.23 \times 0.06 \mathrm{~m}$ was lined with two Kimberley ${ }^{\circledR}$ blue double ply tissues covering the whole base. $50 \mathrm{~mL}$ of swine blood was poured over the tissues. The tray 
was then pushed against the sole of the footwear attached to the rig in a walking motion. The same motion was repeated twice on clean tissues to remove excess blood before releasing the foot onto the fabric.

Six individual repeat footwear marks were prepared as described for all tests undertaken . All impressions were allowed to age for 7 days before enhancement with the various peroxidase reagents. Photography of all impressions was performed immediately after the impression was prepared, after 7 days, after chemical treatment and during fluorescence examination if required.

\section{Diminishing Series}

A diminishing series was prepared by stepping on a blood soaked tissue and then using the footwear rig to produce ten bloody impressions for each fabric with the first one being the most blood-stained. In this case the excess blood was not removed after the initial application. After seven days, the impressions were cut into four pieces and one part was treated with acid yellow 7, a protein stain to provide a comparison for the peroxidase reagents, and the other three parts treated with LCV, LMG and luminol

\section{Washing}

The blood impressions were prepared as detailed previously and left for 48 hours before washing in a Hoover ${ }^{\circledR}$ washing machine with Surf ${ }^{\circledR}$ powder detergent at a temperature of $40^{\circ} \mathrm{C}$ on a normal cycle. The samples were left to dry overnight before chemical treatment using LCV, LMG and luminol. 


\section{RESULTS AND DISCUSSION}

A number of methods are reported for the application of the various peroxidase reagents onto the receiving surface. Sprayers available from Preval ${ }^{\circledR}$, BVDA, Bluestar ${ }^{\circledR}$ and a conventional garden sprayer were all evaluated as a means of reagent delivery for LCV, LMG and Luminol

Diffusion of the original bloody impressions was observed for almost all impressions after application of the reagents using either a garden sprayer or a BVDA sprayer. After several attempts of enhancing bloody impressions, the Bluestar Ecospray ${ }^{\circledR}$ unit proved to be the only spray suitable for enhancing blood impressions without diffusion and obliteration of the original impression for luminol and LCV. The Ecospray ${ }^{\circledR}$ unit delivered a very fine mist and even repetitive light applications of luminol on the same impressions failed to cause diffusion. An example of the result obtained for LCV is illustrated in figure 2.

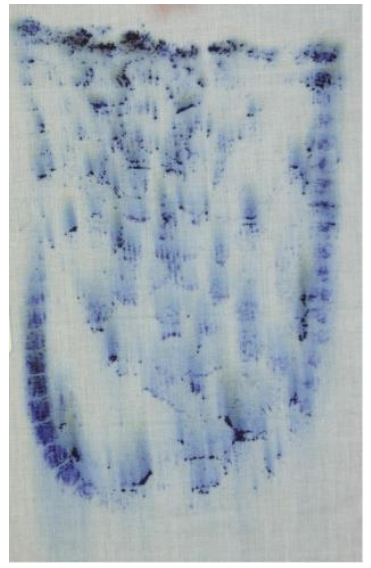

(a)

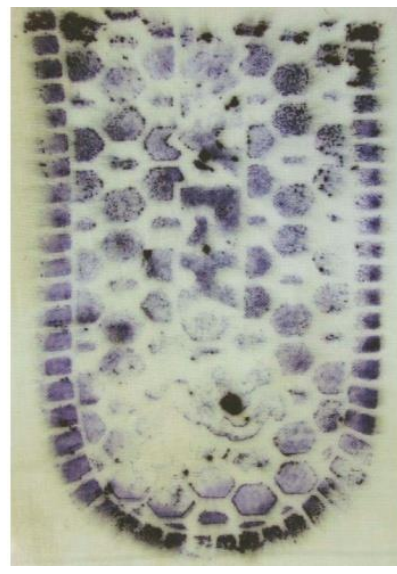

(b)

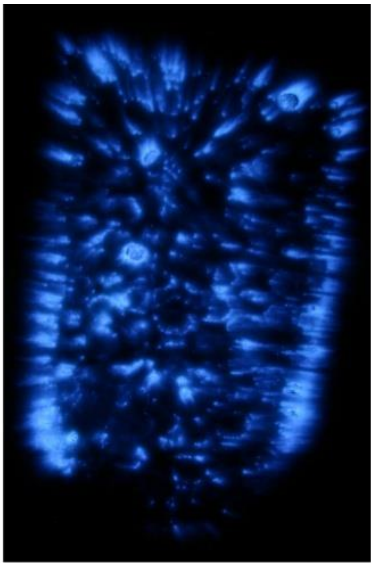

(c)

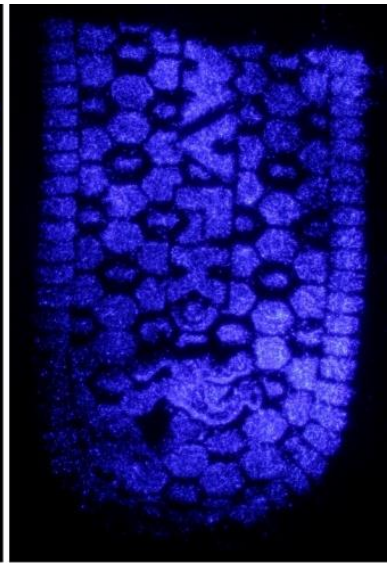

(d)

Figure 2 - Enhancement of footwear impression in blood on white cotton with LCV using: (a) BVDA sprayer; (b) Bluestar ${ }^{\circledR}$ Ecospray; and luminol using: (c) BVDA sprayer; (d) Bluestar $^{\circledR}$ Ecospray

For LMG, the Preval ${ }^{\circledR}$ sprayer provided better enhancement than the Ecospray ${ }^{\circledR}$ unit. This is most likely due to the fact that the fine mist of LMG produced by the Ecospray ${ }^{\circledR}$ unit was not sufficient to produce a vivid colour reaction with blood. 
The purple enhancement during LCV application is due to the haemoglobin catalysing the oxidation reaction of the colourless leuco crystal violet to crystal violet. A well-documented issue with this is that, when exposed to light, the oxidation reaction gradually causes the whole background surface upon which the target impression resides to turn purple $[1-2,11$ 12]. An example of background staining is shown in figure 3. This can limit the operational use of LCV however rapid photography of the impression after the reagent application can offset this limitation. The ease of LCV application (via a spray without the requirement of fixing or de-staining) makes it an attractive enhancement technique for operational use.

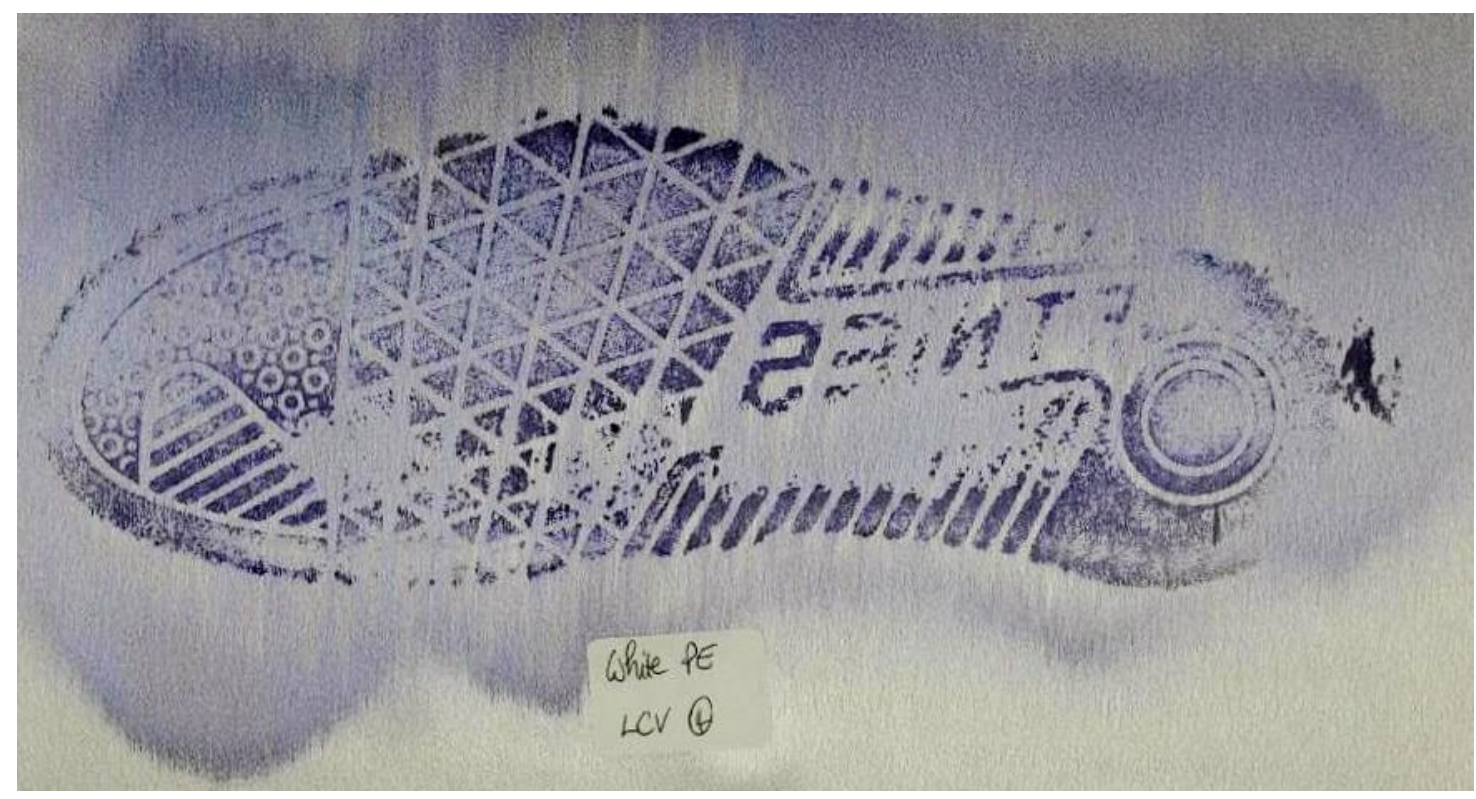

Figure 3 - LCV background staining on white polyester within 30 minutes of application

LCV proved to be a suitable technique for the enhancement of blood impressions on all light coloured fabrics, including cotton (figure 4), polyester, nylon/lycra and leather, but failed to produce consistent enhancement for marks on denim and dark coloured fabrics. Contrary to the literature $[11,13]$, examination of these fabrics using a Quasar with different excitation filters failed to improve the visualisation of the enhanced marks produced, though the application of oblique lighting on black polyester did help visualise the enhanced impression slightly. Other disadvantages associated with the use of LCV concern health and safety and clean up issues [2]. Protein stains can also be applied after LCV. 


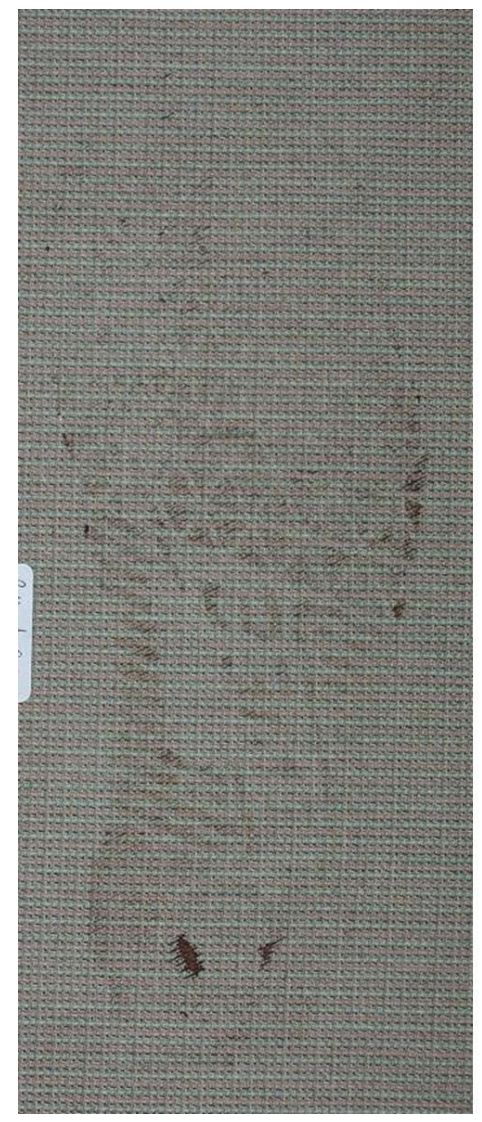

(a)

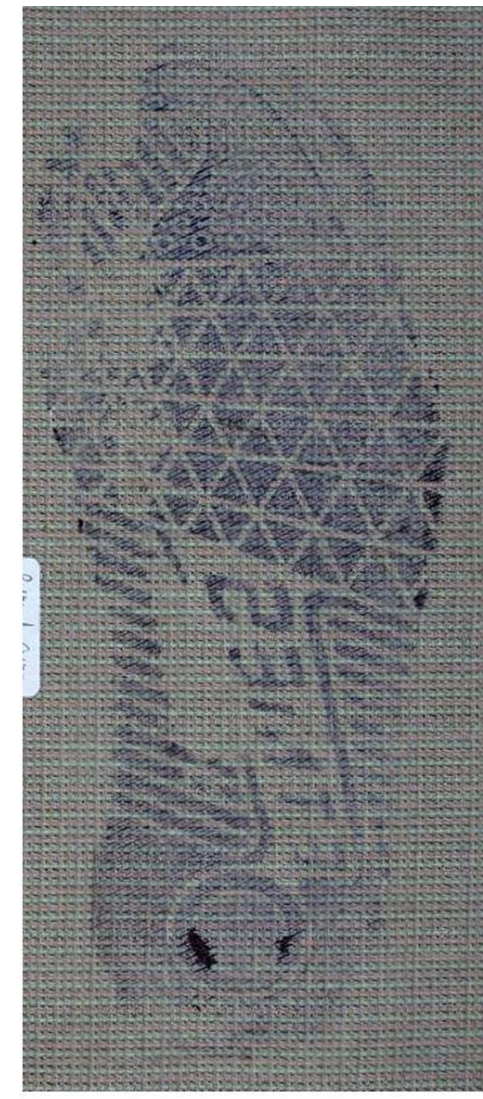

(b)

Figure 4 - Enhancement of a footwear impression in blood on patterned cotton using LCV: (a) before; (b) after

\section{$\underline{L M G}$}

The RCMP formulation [38-39] for LMG recommends pre-fixing the impressions with methanol. Trials carried out during this study showed that fixing the impression with methanol, ethanol or 5-sulfosalicyclic acid resulted in a blurred enhanced impression with less vivid green colours. Repeated spraying of the impression also resulted in blurred impressions and best enhancement was achieved by not fixing the impression prior to application of the reagent. This is illustrated in figure 5 .

LMG enhancement of the footwear impressions in blood performed in a manner similar to LCV, however, background staining did not occur. Sight diffusion of the enhanced impression, minimised by lighter spraying, occurred on white polyester. Enhancement on light coloured fabrics was clear and sharp with a bright vivid green colour being observed as illustrated in figure 6. This is contrary to previous research [2] where the use of LMG was not recommended as the enhancement achieved was described as poor with a pale product colour causing problems with background contrast. 


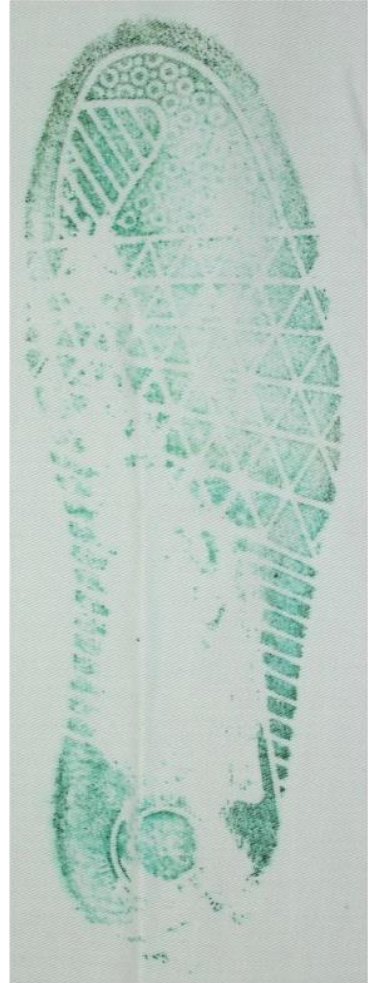

(a)

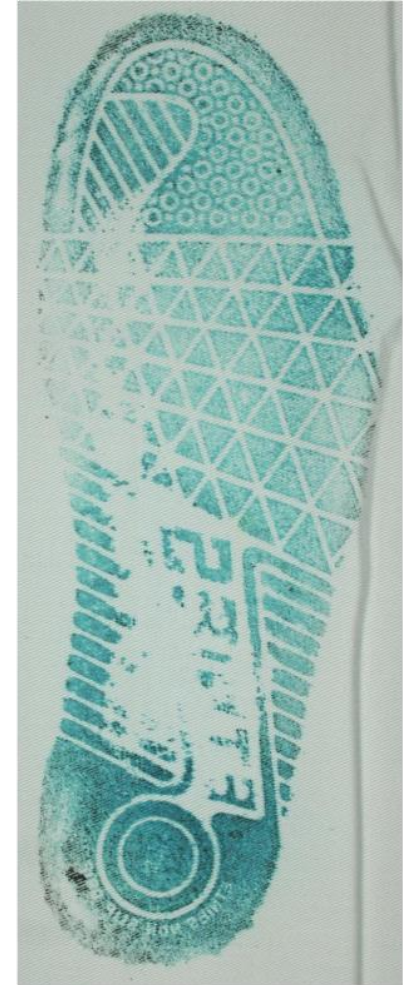

(b)

Figure 5 - Enhancement of a footwear impression in blood on white cotton using LMG: (a) with fix; (b) without fix

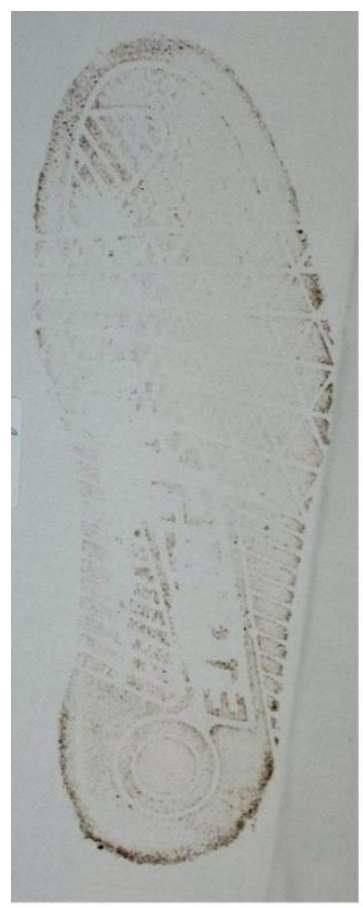

(a)

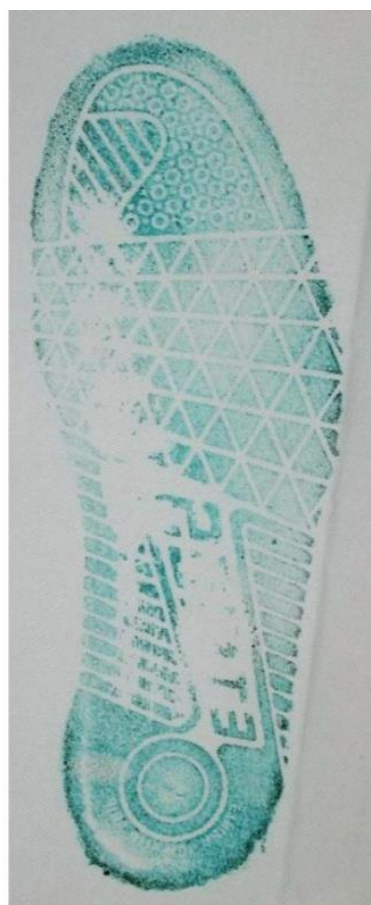

(b)

Figure 6 - Enhancement of a footwear impression in blood on white cotton using LMG: (a) before; (b) after 
Enhancement on dark coloured fabrics including denim and leather was not visible or was poor due to contrast problems. LMG enhancement on black cotton and nylon/lycra seemed to be bright at first glance but disappeared rapidly. This observation was more pronounced for denim (figure 7) where the green colour faded within approximately 30 seconds post application of the reagent. Repeated application of LMG failed to re-enhance the impression.

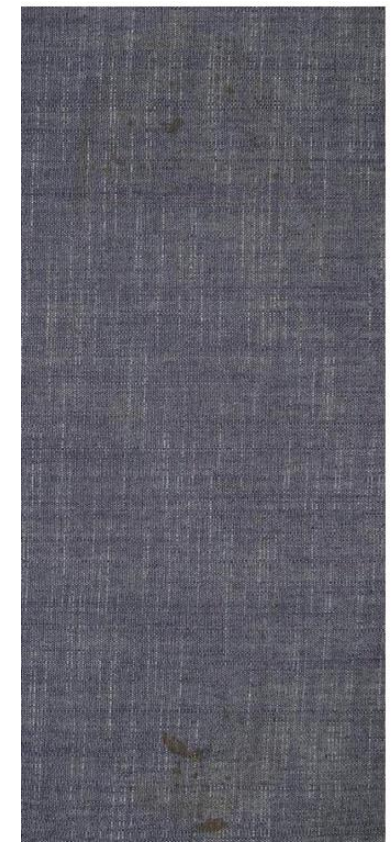

(a)

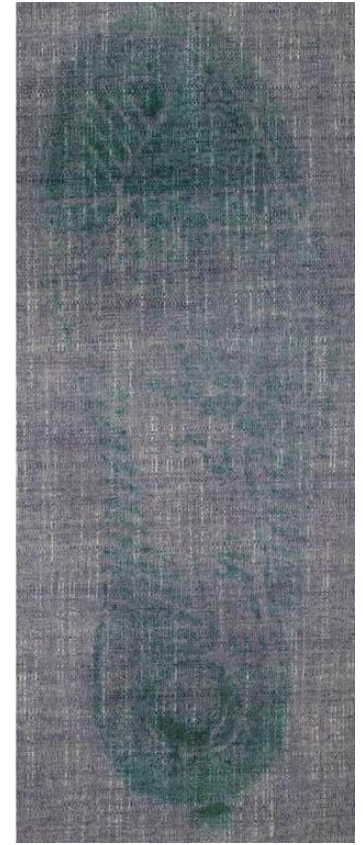

(b)

Figure 7 - Enhancement of a footwear impression in blood on denim using LMG: (a) before; (b) after

\section{Fluorescein}

Fluorescein enhancement was poor on light coloured fabrics and excellent on dark coloured fabrics. The colorimetric reaction occurred almost instantaneously on the dark fabrics and leather, eliminating the requirement for an alternate light source. The visual enhancement on denim was poor, though fluorescence did aid visualisation of the impression on this fabric. Quick capture of the enhanced marks using photography was essential as the bright yellow colour produced on application of the reagents began to fade after a few minutes. Background staining was observed on white cotton, polyester and nylon/lycra as well as patterned cotton which interfered with the fluorescence as illustrated in figure 8 and 9. A tinge of pink also developed with the background staining on the white synthetic fabrics. Contrary to Budowle [19], no fluorescein background staining on denim was observed, either initially or over time 
(figure 10). The application of protein stains and powders can also be performed after fluorescein if further enhancement is necessary.

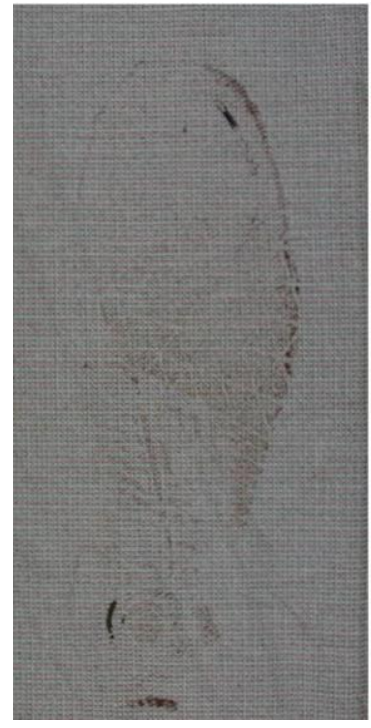

(a)

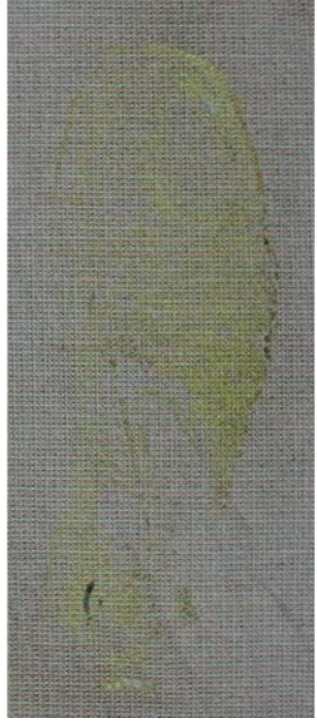

(b)

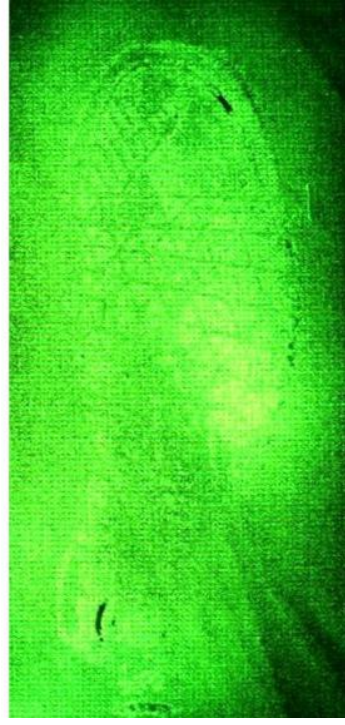

(c)

Figure 8 - Enhancement of a footwear impression in blood on patterned cotton using fluorescein: (a) before enhancement; (b) under white light; (c) using fluorescence

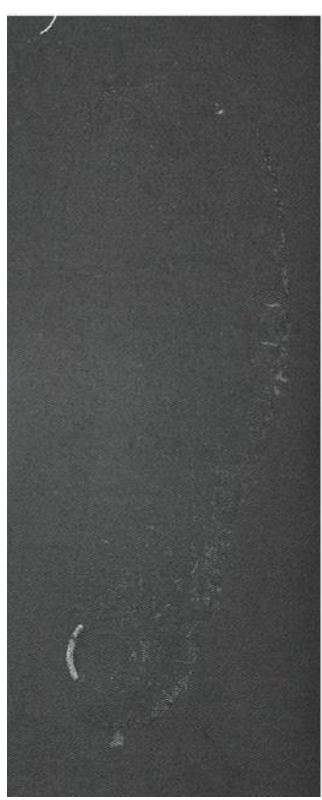

(a)

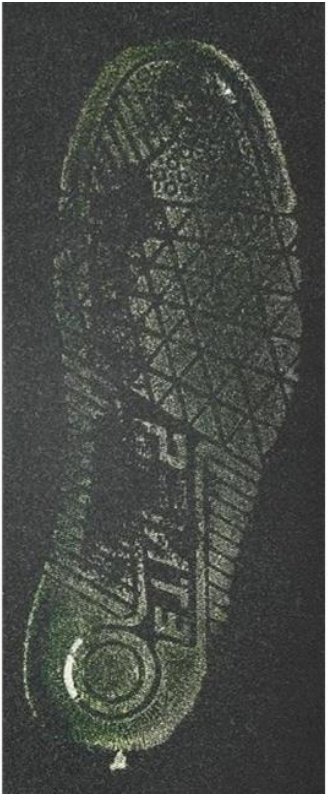

(b)

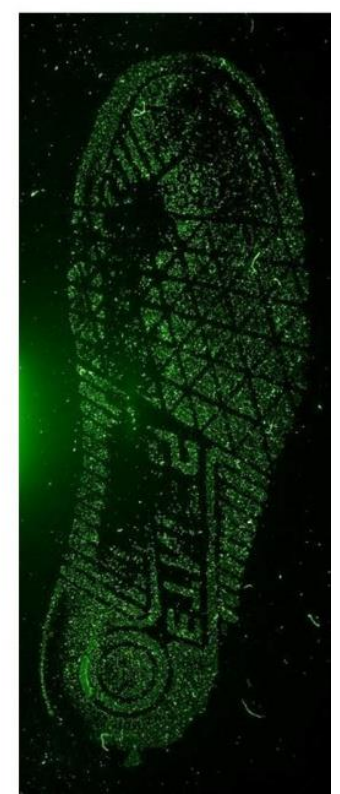

(c)

Figure 9 - Enhancement of a footwear impression in blood on black cotton using fluorescein: (a) before enhancement; (b) under white light; (c) using fluorescence 


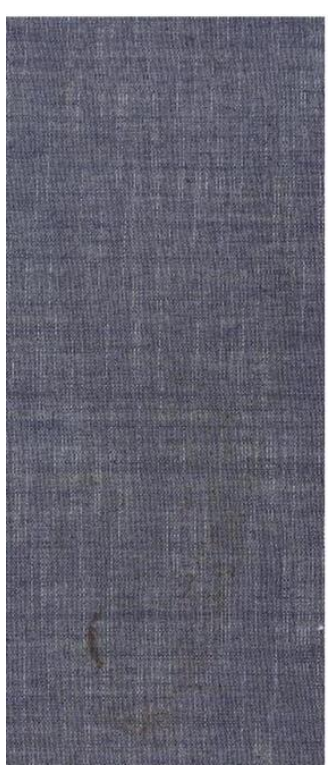

(a)

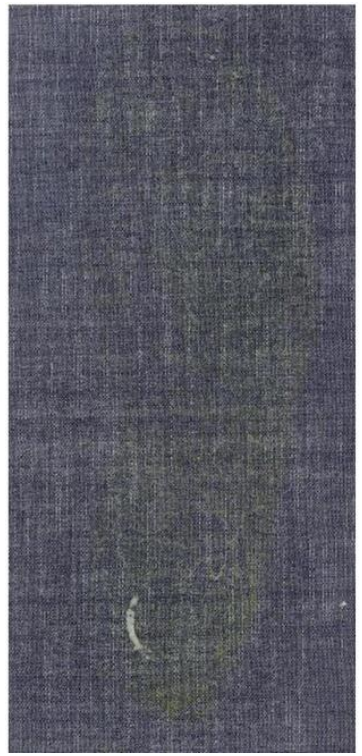

(b)

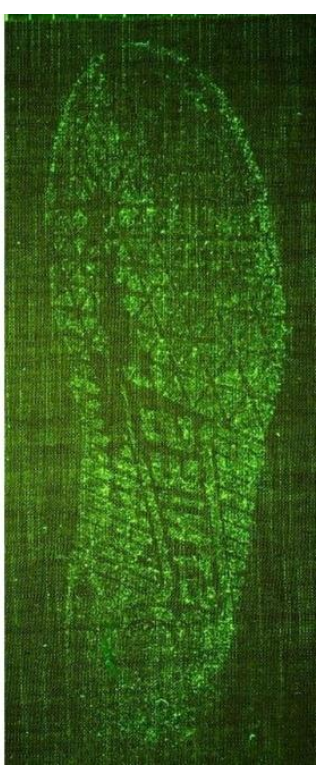

(c)

Figure 10 - Enhancement of a footwear impression in blood on denim using fluorescein: (a) before enhancement; (b) under white light; (c) using fluorescence

\section{$\underline{\text { Luminol }}$}

Luminol proved to be the only technique successful in the enhancement of footwear impressions made in blood irrespective of fabric type of colour. The strongest enhancement on denim was achieved using luminol as illustrated in figure 11. Some diffusion and blurring was observed on the synthetic fabrics polyester and nylon/lycra (figure 12), in particular polyester. Several studies $[16,18,20,35]$ have compared luminol and fluorescein with mixed views on which technique is the most efficient. Both have their advantages and disadvantages, however, in this study luminol performed better overall with fluorescein providing slightly better results on black synthetic fabrics. No background staining was observed with the application of luminol on leather samples even though the reagent is reported to react with chromium and cobalt [40-42] often used in the tanning process. Luminol can be used before protein staining and other heme-reacting dyes. The original impression is not affected by luminol and there is no permanent colouration. 


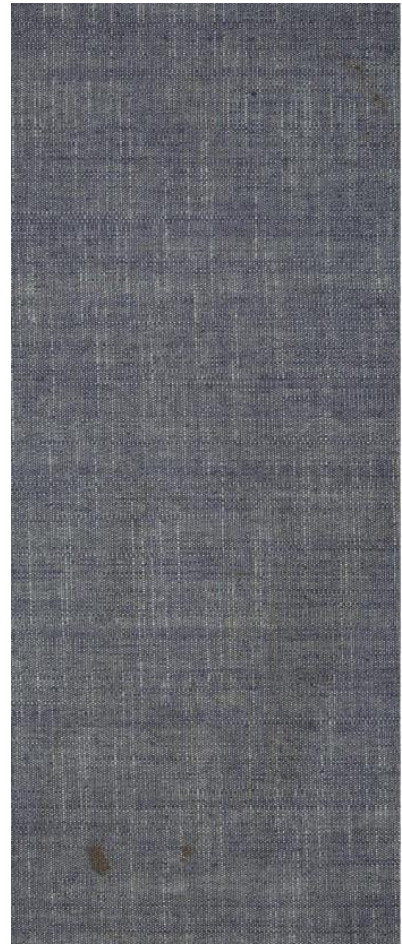

(a)

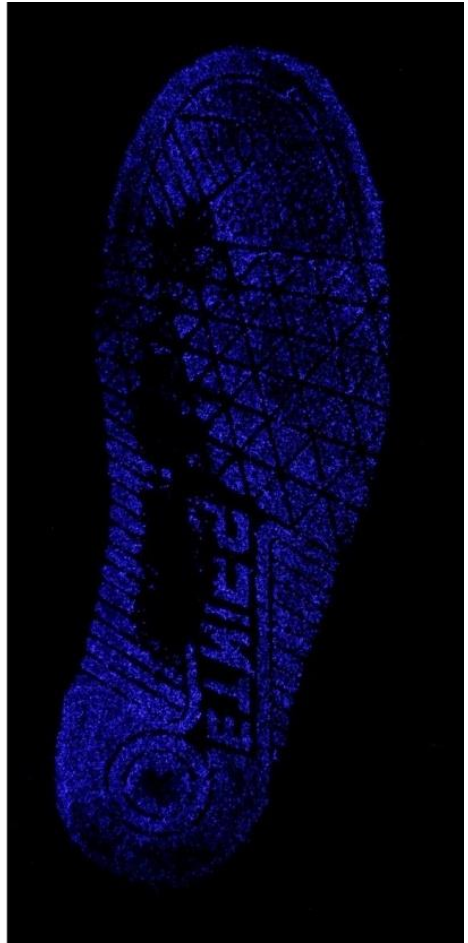

(b)

Figure 11 - Enhancement of a footwear impression in blood on denim using luminol:

(a) before; (b) after

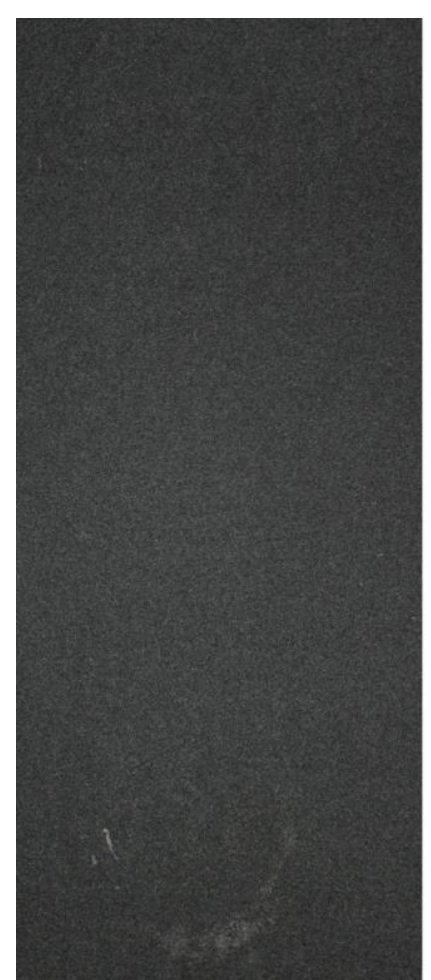

(a)

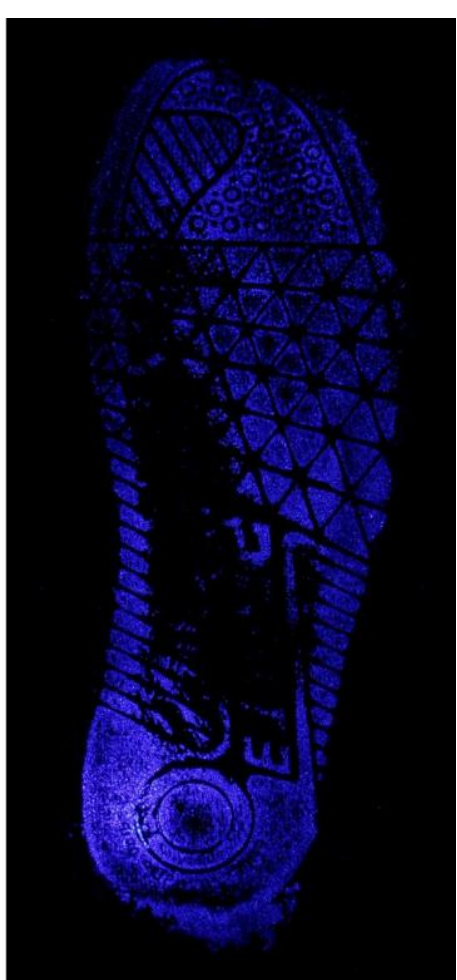

(b)

Figure 12 - Enhancement of a footwear impression in blood on black nylon/lycra using luminol: (a) before; (b) after 


\section{Diminishing Series}

The impressions from the diminishing series were cut into four pieces and treated with LCV, LMG, luminol and one protein stain (acid yellow 7) to provide an alternative fluorescence source by way of contrast. Figure 13 shows an example of four pieces from a blood impression treated with the different enhancement techniques.

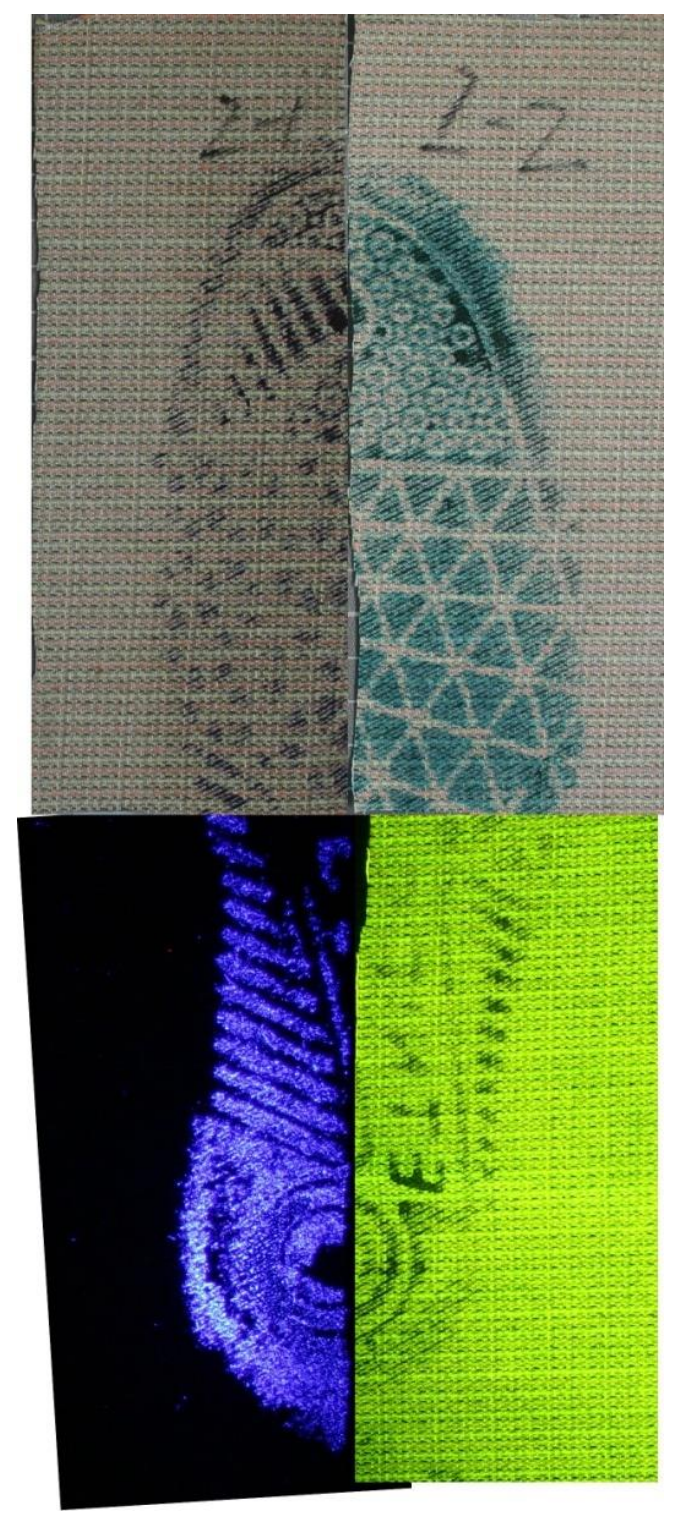

Figure 13 - The second impression of a diminishing series on patterned cotton treated with 4 different techniques (from top right going clockwise: LCV, LMG, acid yellow 7 and luminol) 


\section{$\underline{L M G \text { and } L C V}$}

The results obtained for the full diminishing series for LCV, LMG and luminol are illustrated in figures 14 to 16. As previously discussed, both LMG and LCV enhancement on dark coloured fabrics did not provide good contrast. Nonetheless, the first two blood impressions prepared on dark fabrics were enhanced, presumably due to heavier blood staining. No marks on black polyester were enhanced by either reagent regardless of the quantity of blood imparted onto the fabric. Blood impressions on the light coloured fabric were enhanced with LMG and LCV up to the fourth or fifth impression. Diffused enhancement was observed on white polyester for both of these reagents.

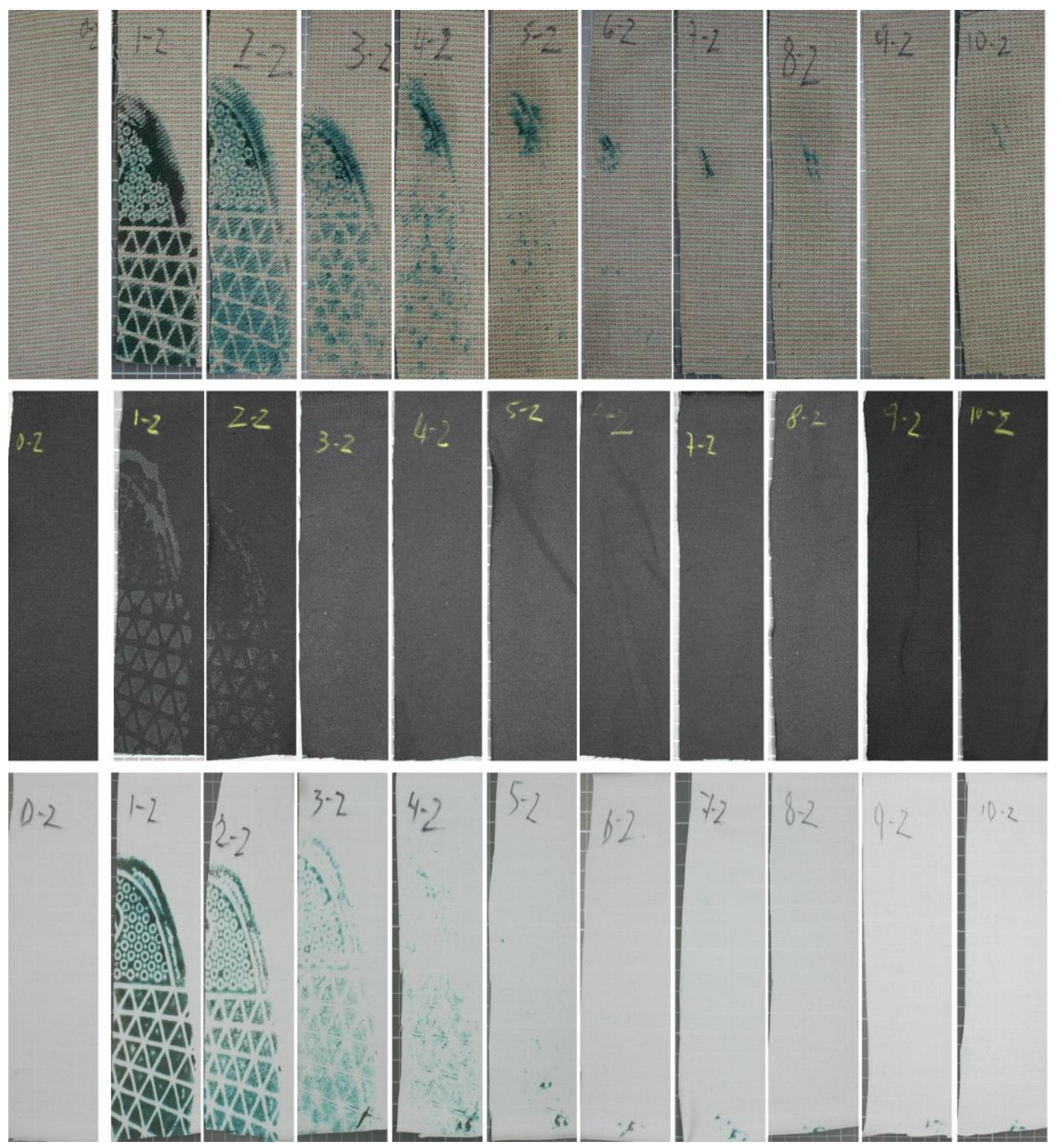

Figure 14 - LMG enhancement for a diminishing series in blood for: patterned cotton, black cotton and white nylon/lycra 


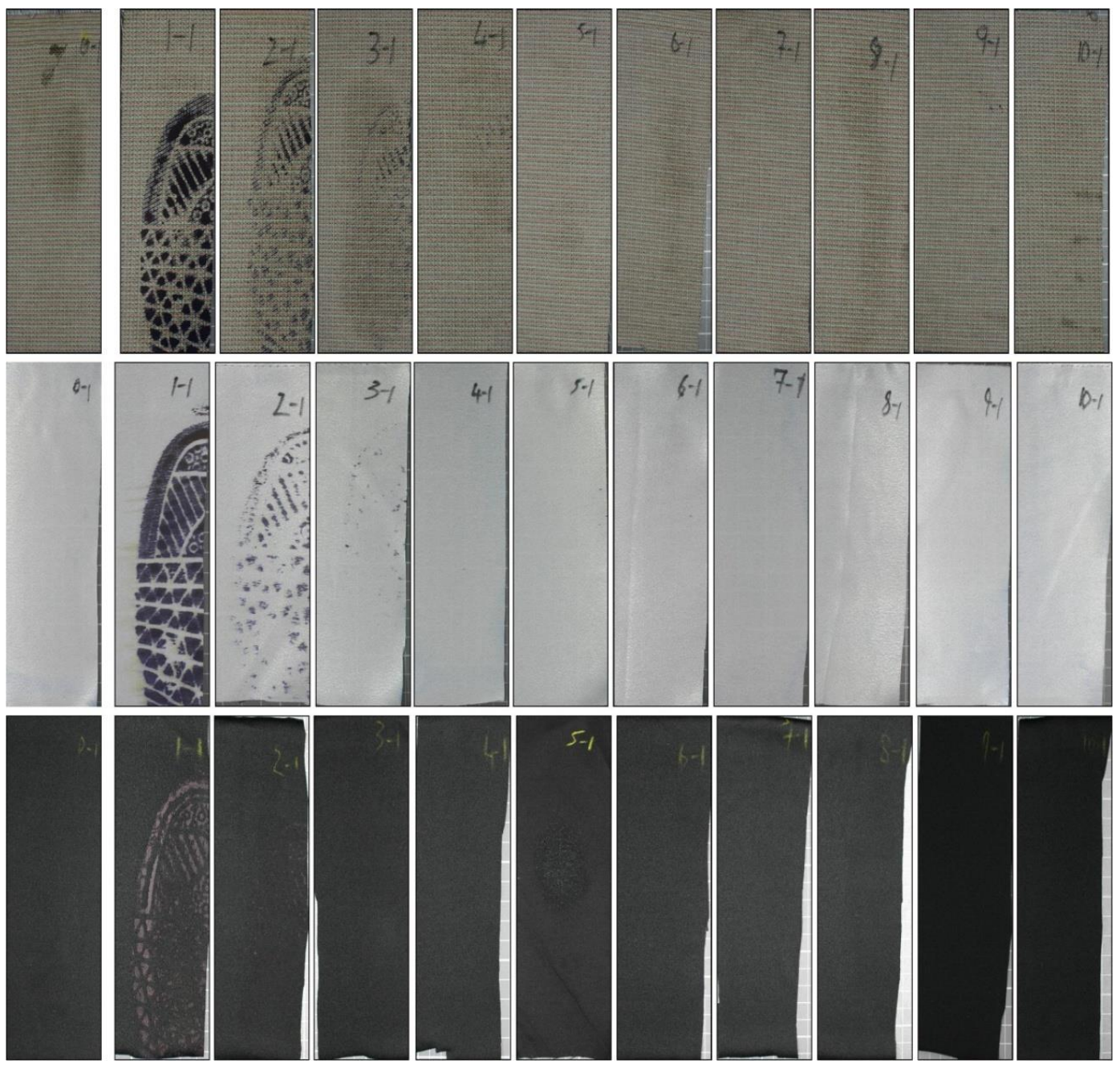

Figure 15 - LCV enhancement for a diminishing series in blood for: patterned cotton, white polyester and black nylon/lycra

\section{Luminol}

Luminol has been widely reported for its sensitivity in the enhancement of blood stains $[2,8]$ and it was hypothesised that luminol enhancement of the diminishing footwear impression series would be successful beyond the fifth impression. However, the results demonstrated that, although luminol detected blood up to the tenth impression on most fabrics, the entire footwear sole could only be visualised up to the third or fourth impression at most. These results suggest that the footwear sole loses a lot of the accumulated blood after the first few impressions. 


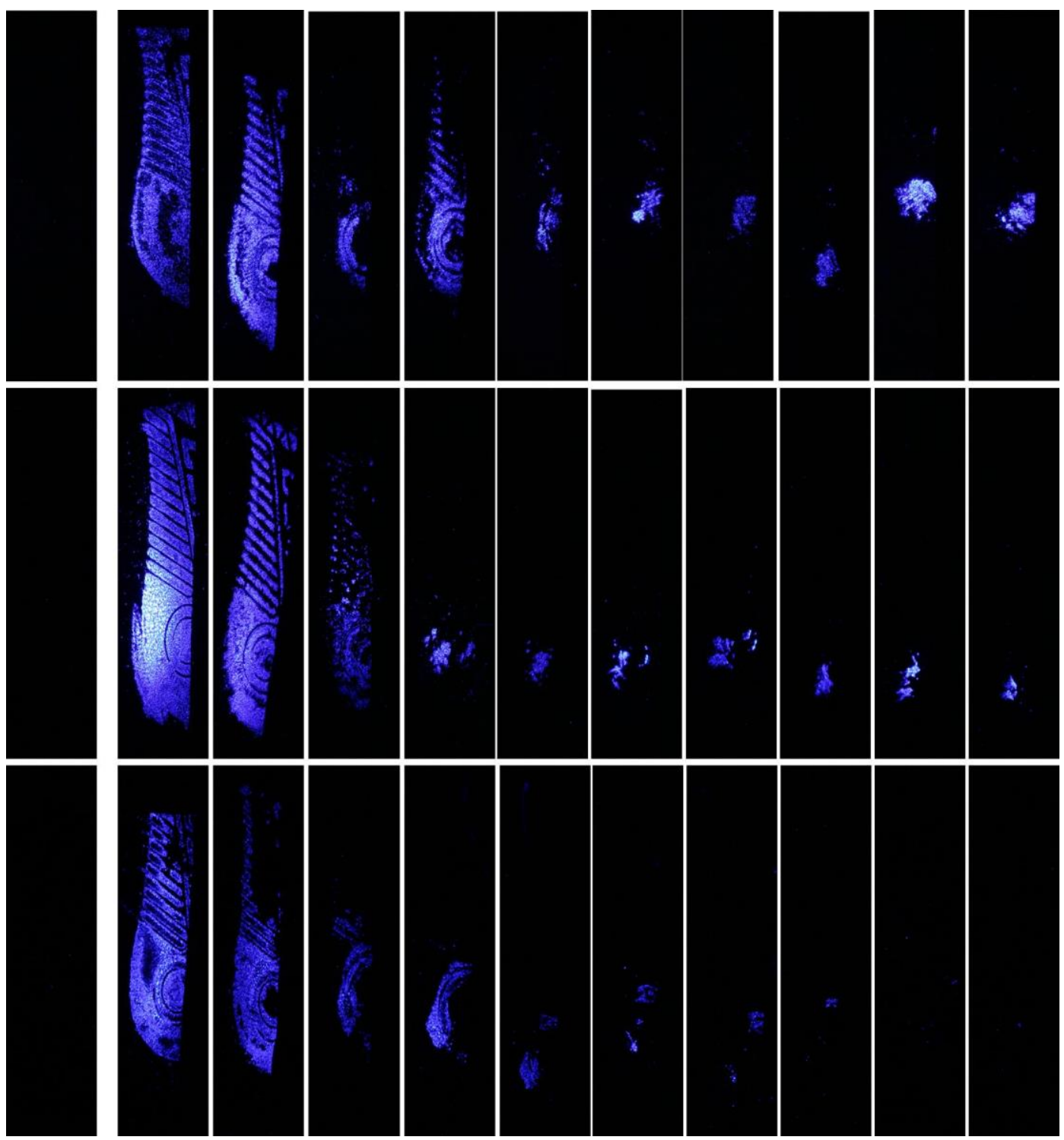

Figure 16 - Luminol enhancement for a diminishing series in blood for: patterned cotton, black nylon/lycra and leather 


\section{Acid yellow 7}

AY7 provided better development of the blood impressions on black fabrics only and struggled to enhance past the first impression on denim and leather.

\section{Washing}

No enhancement of the footwear impressions was observed after washing and air drying for any of the reagents studied, although luminol showed slight scattered dots of chemiluminescence, possibly indicating the presence of blood. This is in contradiction to previous research [43-44] where blood was detected using luminol and other techniques after washing. This contradiction can possibly be explained by the fact that in this study, weak latent blood impressions were prepared whereas in other studies heavier bloodstained impressions were used. Cox [44] also observed a relationship between the type of fabric and the retention of the bloodstains where blood was likely to wash off synthetic fabrics such as acetate, nylon and polyester. 


\section{CONCLUSION}

The aim of this work was to provide a comprehensive comparison of the ability of a number of peroxidase reagents to enhance footwear impressions made in blood on a range of fabric types and colours. The methodology chosen deliberately controlled the means by which the impressions were produced and the quantity of blood used in each case so that the enhancement ability of the reagent was the only uncontrolled variable thus facilitating a true comparison between the reagents.

Of the four peroxidase reagents studied, luminol was the best performing enhancement technique overall, enhancing impressions on all surfaces and was the only technique to provide a clear enhancement of the impressions on denim. LCV and LMG provided good enhancement on patterned cotton and light coloured fabrics but were poor enhancers of impressions on darker fabrics whereas fluorescein and luminol yielded excellent enhancement results on black and dark coloured fabrics.

In general luminol was the more efficient reagent for weaker impressions and provided good footwear detail up to the fifth impressed mark in a series and detected blood up to the tenth impression for most fabrics where as the other reagents provided little enhancement past the second or third impression in the series.

In this work none of the peroxidase reagents successfully enhanced impressions in blood that had been subjected to washing. 


\section{ACKNOWLEDGEMENTS}

The authors would like to thank HOSDB, EPSRC and the University of Strathclyde for their continued financial support. This work is also partially funded by the Malta Government Scholarship Scheme. 


\section{REFERENCES}

1. James, S.H., Kish, P.E., and Sutton, T.P., Principles of Bloodstain Pattern Analysis: Theory and Practice, 3rd Edition ed. 2005, FL: CRC Taylor and Francis Group LLC.

2. Powell, L., Enhancing Footwear Marks Made in Blood, in Centre for Forensic Science. 2008, University of Strathclyde: Undergraduate Final Year Project: Glasgow.

3. Gaensslen, R.E., Sourcebook in Forensic Serology, Immunology and Biochemistry. 1983, Washington DC: U.S. Department of Justice.

4. Horobin, R.W. and Kiernan, J.A., Conn's biological stains : a handbook of dyes, stains and fluorochromes for use in biology and medicine 10th ed. 2002: Oxford.

5. Horobin, R.W., Histochemistry - An Explanatory Outline of Histochemistry and Biophysical Staining. 1982, London: Butterworths.

6. Green, F.J., The Sigma-Aldrich Handbook of Stains, Dyes and Indicators. 1990: Aldrich Chemical Company, Milwaukee.

7. Grodsky, M., Wright, K., and Kirk, P.L., Simplified Preliminary Blood Testing. An Improved Technique and a Comparative Study of Methods, The Journal of Criminal Law, Criminology, and Police Science, 1951, 42(1): p. 95-104.

8. $\quad$ Sears, V.G., Butcher, C.P.G., and Fitzgerald, L.A., Enhancement of Fingerprints in Blood Part 3: Reactive Techniques, Acid Yellow 7, and Process Sequences, Journal of Forensic Identification, 2005, 55(6): p. 741-763.

9. Stow, K., Direct Lift-Enhancement of Blood-Contaminated Shoe Marks by Leuco Malachite Green-Impregnated Membranes, Science and Justice, 1994, 34(4).

10. Michaud, A.L. and Brun-Conti, L., A Method for Impregnating Nylon Transfer Membranes with Leucocrystal violet for Enhancing and Lifting Bloody Impressions, Journal of Forensic Science, 2004, 49(3): p. 511-516.

11. Bodziak, W.J., Use of leuco crystal violet to enhance shoe prints in blood, Forensic Science International, 1996, 82(1): p. 45-52.

12. Bodziak, W.J., Footwear Impression Evidence: Detection, Recovery and Examination, 2nd ed. 2000, London: CRC Boca Raton.

13. Spence, L. and Asmussen, G., Spectral Enhancement of Leucocrystal Violet Treated Footwear Impression Evidence in Blood, Forensic Science International, 2003, 137(2): p. 117-124.

14. Theeuwen, A.B.E., van Barneveld, S., Drok, J.W., Keereweer, I., Limborgh, J.C.M., Naber, W.M., and Velders, T., Enhancement of Footwear Impressions In Blood, Forensic Science International, 1998, 95(2): p. 133-151.

15. Cheeseman, R. and DiMeo, L.A., Fluorescein as a Field-Worthy Latent Bloodstain Detection System, Journal of Forensic Identification, 1995, 45(6): p. 631-646.

16. Cheeseman, R., Direct Sensitivity Comparison of the Fluorescein and Luminol Bloodstain Enhancement Techniques, Journal of Forensic Identification, 1999, 49(3): p. 261-268.

17. Cheeseman, R. and Tomboc, R., Fluorescein Technique Performance Study on Bloody Foot Trails, Journal of Forensic Identification, 2001, 51(1): p. 16-27.

18. Barbaro, A., Cormaci, P., and Teatino, A., Validation of forensic DNA analysis from bloodstains treated by presumptive test reagents, International Congress Series, 2004, 1261(Progress in Forensic Genetics): p. 631-633.

19. Budowle, B., Leggitt, J.L., Defanbaugh, D.A., Keys, K.M., and Malkiewicz, S.F., The Presumptive Reagent Fluorescein for the Detection of Dilute Bloodstains and subsequent STR Typing of Recovered DNA, Journal of Forensic Science, 2000, 45(5): p. 1090-1092.

20. Jakovich, J., STR Analysis Following Latent Blood Detection by Luminol, Fluorescein, and Blustar, Journal of Forensic Identification, 2007, 57(3): p. 193.

21. Martin, L.A. and Cahill, C.F., Recovery of DNA from Latent Blood after Identification by Fluorescein, Journal of Forensic Identification, 2004, 54(6).

22. Bily, C. and Maldonado, H., The Application of Luminol to Bloodstains Concealed by Multiple Layers of Paint, Journal of Forensic Identification, 2006, 56(896-906). 
23. Dilbeck, L., Use of Bluestar Forensic in lieu of Luminol at Crime Scenes, Journal of Forensic Identification, 2006, 56(5): p. 706-729.

24. Blum, L.J., Esperanca, P., and Rocquefelte, S., A New High Performance Reagent and Procedure for Latent Bloodstain Detection based on Luminol Chemiluminescence, Journal of the Canadian Society of Forensic Science, 2006, 39(3): p. 81-100.

25. Quickenden, T.I. and Cooper, P.D., Increasing the Specificity of the Forensic Luminol Test for Blood, Luminescence, 2001, 16: p. 251-253.

26. King, R. and Miskelly, G.M., The Inhibition by Amines and Amino Acids of Bleach-Induced Luminol Chemiluminescence during Forensic Screening for Blood, Talanta, 2005, 67: p. 345-353.

27. Kent, E.J.M., Elliot, D.A., and Miskelly, G.M., Inhibition of Bleach-Induced Luminol Chemilumescence, Journal of Forensic Science, 2003, 48(1): p. 1-4.

28. Creamer, J.I., Quickenden, T.I., Crichton, L.B., Robertson, P., and Ruhayel, R.A., Attempted Cleaning of Bloodstains and its Effect on the Forensic Luminol test, Luminescence, 2005, 20: p. 411-413.

29. Arnhold, J., Mueller, S., Arnold, K., and Grimm, E., Chemiluminescence Intensities and Spectra of Luminol Oxidation by Sodium Hypochlorite in the Presence of Hydrogen Peroxide, Journal of Bioluminescence and Chemilumescence, 1991, 6(3): p. 189-192.

30. Gross, A.M., Harris, K.A., and Kaldun, G.L., The Effect of Luminol on the Presumptive Tests and DNA Analysis using the Polymerase Chain Reaction, Journal of Forensic Science, 1999, 44(4): p. 837-840.

31. Barni, F., Lewis, S.W., Berti, A., Miskelly, G.M., and Lago, G., Forensic Application of the Luminol Reactions as a Presumptive Test for Latent Blood Detection, Talanta, 2007, 72: p. 896-913.

32. Webb, S.K., Luminol vs Bluestar: A Comparison Study of Latent Blood Reagents, in Technical Note from the Saint Louise Metropolitan Police.

33. Hill, L., A Spectrosopic Analysis of the Four Most Common Formulations of Luminol, in Centre for Forensic Science. 2008, University of Strathclyde M.Sc.: Glasgow.

34. Hochmeister, M.N., Budowle, B., Sparkes, R., Rudin, O., Gehrig, C., Thali, M., Schmidt, L., Cordier, A., and Dirnhofer, R., Validation Studies of an Immunochromatographic 1-Step Test for the Forensic Identification of Human Blood, Journal of Forensic Science, 1999, 44(3): p. 597-602.

35. Young, T., A Photographic Comparison of Luminol, Fluorescein and Bluestar, Journal of Forensic Identification, 2006, 56(6): p. 906-913.

36. Watkins, M.D. and Brown, K.C., Blood Detection: A Comparison of Visual Enhancement Chemicals for the Recovery of Possible Bloodstains at the Crime Scene, Luminol Vs Bluestar, in Rouget Communication. Undated, Bluestar: France.

37. Ellis, E.L., Wong, T.P., and Bowers, S.W., Locating Latent Bloodstains, Journal of Forensic Identification, 2009, 59(1): p. 59-64.

38. Wilkinson, D. RCMP Fingerprint Development Techniques - Leucomalachite Green. 2001 23/10/2009]; Available from: http://www.rcmp-grc.gc.ca/fsis-ssji/firs-srij/reciperecette/leuco-eng.htm.

39. Frégeau, C.J., Germain, O., and Fourney, R.M., Fingerprint Enhancement Revisited and the Effects of Blood Enhancement Chemicals on Subsequent Profiler Plus ${ }^{\mathrm{TM}}$ Fluorescent Short Tandem Repeat DNA Analysis of Fresh and Aged Bloody Fingerprints, Journal of Forensic Science, 2000, 45(2): p. 354-380.

40. Bause, D.E. and Patterson, H.H., Enhancement of luminol chemiluminescence with halide ions, Analytical Chemistry, 1979, 51(13): p. 2288-2289.

41. Chang, C.A. and Patterson, H.H., Halide ion enhancement of chromium(III), iron(II), and cobalt(II) catalysis of luminol chemiluminescence, Analytical Chemistry, 1980, 52(4): p. 653-656. 
42. Lin, J.-M., Shan, X., Hanaoka, S., and Yamada, M., Luminol Chemiluminescence in Unbuffered Solutions with a Cobalt(II)-Ethanolamine Complex Immobilized on Resin as Catalyst and Its Application to Analysis, Analytical Chemistry, 2001, 73(21): p. 5043-5051.

43. Adair, T. and Shaw, R.L., Enhancement of Blood Stains on Washed Clothing using Luminol and LCV Reagents, IABPA News, 2005, (December): p. 4-10.

44. Cox, M., Effect of Fabric Washing on the Presumptive Identification of Bloodstains, Journal of Forensic Science, 1990, 35(6): p. 1335-1341. 